\title{
Delayed Surgical Management of Type A Intramural Hematoma Is Not Associated with Worse Outcomes Than Emergent Operation
}

\author{
Xun Zhou, MD, Aravind Krishnan, BA, Joshua Hsu, BA, Austin Burns, BA, Kaushik Mandal, MD \\ Division of Cardiac Surgery, Department of Surgery, Johns Hopkins University School of Medicine, Baltimore, MD, USA
}

\section{ABSTRACT}

Objectives: Management of acute aortic intramural hematomas (IMHs) involving the ascending aorta and root remains controversial. Some series have suggested that delaying operative intervention beyond the first 24-hours may be beneficial.

Methods: A retrospective single-institution analysis was performed to identify patients presenting with type A IMH. These patients were classified by whether they underwent surgery within 24 hours or delayed operative intervention. Patients with additional indications for emergent operation, such as acute aortic regurgitation or malperfusion syndromes, were excluded. Outcomes were assessed with logistic regression, and the Kaplan-Meier method was used to analyze long-term survival.

Results: Of the 129 patients with acute type A aortic pathology, 36 (27.9\%) presented with isolated IMH. IMH patients were less likely to present with acute aortic regurgitation $(8.6 \%$ versus $27.9 \%, P=.020)$ or limb ischemia $(0 \%$ versus $12.6 \%, P=.027)$. Of the IMH patients without other emergent operative indications, 23 (67.6\%) underwent surgery within 24 hours. Delayed operative repair was not associated with increased risk of mortality, stroke, or renal failure (all $P>.05$ ). Survival analysis showed no difference in survival at 1 year.

Conclusions: In well-selected patients, delayed operation for type An intramural hematoma is not associated with adverse outcomes.

\section{BACKGROUND}

Acute aortic syndrome represents a spectrum of pathology ranging from aortic dissection and penetrating atherosclerotic ulcer to intramural hematoma. Classically, the presence of a Stanford type A aortic dissection has necessitated emergent operative repair, given the grave threat to life associated with

Received November 13, 2018; accepted fanuary 2, 2019.

Current affiliation: K.M., Division of Cardiac Surgery, Penn State University School of Medicine \& Milton S Hershey Medical Center, Hershey, PA.

Correspondence: Xun Zhou, Fohns Hopkins Hospital, Blalock Building, Room 1265, 600 North Wolfe Street, Baltimore, MD 21287; 1-410-614-5283; fax: 1-443-287-4226 (xzhou31@jhmi.edu). the natural history of the disease. However, although great strides have been made in refining the surgical management of type A aortic dissections, the operation remains associated with significant morbidity and mortality [Trimarchi 2005].

The management of acute aortic intramural hematomas (IMHs) involving the ascending aorta and root remains controversial. Because the pathophysiology of IMH and risk of catastrophic complication may be lower than other acute aortic pathologies, some series have suggested that delaying operative intervention beyond the first 24 hours may be beneficial [Sandhu 2016]. We sought to review our institutional case series of the management of type A IMH.

\section{Methods}

A single-institution retrospective analysis was performed to identify patients presenting with type A acute aortic pathology between the years of 1990 and 2018. Patients were stratified by the presence or absence of IMH in the aortic root or ascending aorta on computed tomography. IMH patients were classified by whether they underwent surgery within 24 hours or delayed operative intervention. Following classification, patients with both a dissection flap and intramural hematoma, or additional indications for emergent operation, such as acute aortic regurgitation or malperfusion syndromes, were excluded from the primary analysis.

The primary outcome was all-cause mortality. The major morbidities recognized by the Society of Thoracic Surgeons (stroke, pneumonia, atrial fibrillation, prolonged intubation, and renal failure) were analyzed as secondary outcomes. Student $t$ test and the chi-square test of independence were used

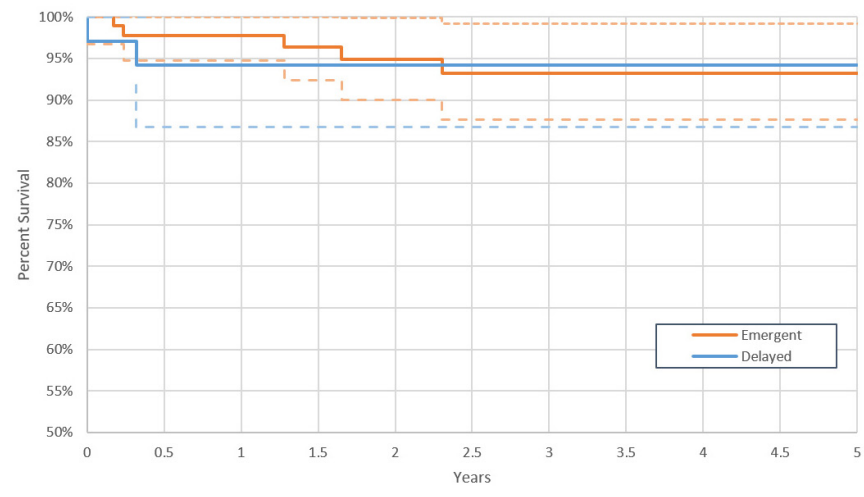

Kaplan-Meier survival comparing emergent and delayed operations. Ninety-five percent confidence intervals expressed by dashed lines. 
Table 1. Baseline Characteristics of Patients Presenting with Acute Aortic Syndrome

\begin{tabular}{|c|c|c|c|}
\hline Demographics & No Hematoma* & $\begin{array}{l}\text { Intramural } \\
\text { Hematoma* }\end{array}$ & $P$ \\
\hline Age, years (SD) & $55.4(15.1)$ & $60.4(18.1)$ & .35 \\
\hline Gender, male & $74(79.6 \%)$ & $16(44.4 \%)$ & $<.001$ \\
\hline \multicolumn{4}{|l|}{ Ethnicity } \\
\hline White & $50(53.8 \%)$ & $23(63.9 \%)$ & .34 \\
\hline African American & $33(35.5 \%)$ & $9(25.0 \%)$ & .40 \\
\hline Hispanic & $0(0.0 \%)$ & $2(5.6 \%)$ & .33 \\
\hline Body mass index & & & .470 \\
\hline \multicolumn{4}{|l|}{ Past medical history } \\
\hline Hypertension & 79 (84.9\%) & $30(83.3 \%)$ & .97 \\
\hline Diabetes & $5(4.3 \%)$ & $8(22.2 \%)$ & .006 \\
\hline Peripheral arterial disease & $3(3.2 \%)$ & $1(2.8 \%)$ & .57 \\
\hline Stroke & $71(76.3 \%)$ & $6(1.7 \%)$ & .99 \\
\hline Chronic lung disease & $6(6.5 \%)$ & $3(8.3 \%)$ & .64 \\
\hline End-stage renal disease & $4(4.3 \%)$ & $1(2.8 \%)$ & .59 \\
\hline Congestive heart failure & $9(9.7 \%)$ & $2(5.6 \%)$ & .32 \\
\hline Atrial fibrillation & $1(1.1 \%)$ & $1(2.7 \%)$ & .58 \\
\hline \multicolumn{4}{|l|}{ Preoperative lab results } \\
\hline Hematocrit, vol\% (SD) & $36.73(6.16)$ & $34.83(7.04)$ & .37 \\
\hline $\begin{array}{l}\text { Platelet count, } \times 1000 / \mu \mathrm{L} \text {, } \\
\text { no. (SD) }\end{array}$ & $193.6(91.1)$ & $167.0(56.2)$ & .31 \\
\hline INR (SD) & $1.20(0.28)$ & $1.13(0.17)$ & .35 \\
\hline \multicolumn{4}{|l|}{ Findings at presentation } \\
\hline Aortic regurgitation & $24(27.9 \%)$ & $3(8.6 \%)$ & .02 \\
\hline Coronary involvement & $9(10.3 \%)$ & $2(5.7 \%)$ & .423 \\
\hline Pericardial effusion & $20(23.0 \%)$ & $8(22.9 \%)$ & .988 \\
\hline Limb ischemia & $11(12.6 \%)$ & $0(0.0 \%)$ & .027 \\
\hline Acute renal failure & $6(6.9 \%)$ & $3(8.6 \%)$ & .751 \\
\hline
\end{tabular}

*Data is $\mathrm{n}(\%)$ unless otherwise indicated.

to compare baseline characteristics between groups. The primary and secondary outcomes were analyzed by using logistic regression. Survival analysis was performed with the KaplanMeier method.

\section{RESULTS}

A total of 129 patients were identified with acute type A aortic pathology. Of them, 36 (27.9\%) presented with IMH. Patients with and without IMH had similar ages and distributions of ethnicities, although IMH patients were less likely to be male. Past medical history was similar between the 2 groups, although IMH patients were significantly
Table 2. Logistic Regression of Outcomes Comparing Patients with and without Intramural Hematoma

\begin{tabular}{|c|c|c|c|c|}
\hline \multirow[b]{3}{*}{ Outcome } & \multicolumn{2}{|c|}{ Estimate } & \multirow[b]{2}{*}{ Odds Ratio (95\% } & \multirow[b]{3}{*}{$P$} \\
\hline & No & & & \\
\hline & Hematoma & Hematoma & Confidence Interval) & \\
\hline 30-Day mortality & $1.8 \%$ & $4.7 \%$ & $2.63(0.36-19.32)$ & .34 \\
\hline Pneumonia & $8.9 \%$ & $8.3 \%$ & $0.94(0.18-4.83)$ & .94 \\
\hline Sepsis & $10.3 \%$ & $7.7 \%$ & $0.72(0.07-7.68)$ & .79 \\
\hline Stroke & $18.5 \%$ & $10.0 \%$ & $0.49(0.16-1.53)$ & .22 \\
\hline $\begin{array}{l}\text { Acute renal } \\
\text { failure }\end{array}$ & $20.3 \%$ & $24.0 \%$ & $1.24(0.43-3.62)$ & .69 \\
\hline Atrial fibrillation & $31.6 \%$ & $29.2 \%$ & $0.89(0.33-2.42)$ & .82 \\
\hline $\begin{array}{l}\text { Prolonged } \\
\text { intubation }\end{array}$ & $64.6 \%$ & $66.7 \%$ & $1.10(0.42-2.88)$ & .85 \\
\hline Readmission & $15.7 \%$ & $25.9 \%$ & $1.88(0.67-5.27)$ & .23 \\
\hline
\end{tabular}

more likely to have diabetes $(22.2 \%$ versus $4.3 \%, P=.006)$ (Table 1).

IMH patients were less likely to present with an emergent indication for surgical intervention. In particular, they were less likely to have aortic regurgitation $(8.6 \%$ versus $27.9 \%, P$ $=0.020)$ or limb ischemia $(0 \%$ versus $12.6 \%, P=.027)$. Rates of coronary involvement, pericardial effusion, or renal failure were similar between the 2 groups. Preoperatively, both groups had similar hematocrit level, platelet count, and prothrombin time. A significant proportion of the patients with IMH had hematoma involvement in the aortic root $(\mathrm{n}=6$, $18.8 \%)$ or extension to the descending aorta $(\mathrm{n}=17,51.5 \%)$, but outcomes following operative management were similar when they were analyzed in logistic regression (Table 2).

Of the patients who presented with type A IMH without an emergent indication for surgery, 23 (67.6\%) underwent operative intervention within 24 hours. There was no statistically significant difference in demographics, past medical history, or risk factors between patients who underwent surgery early or late. Both groups had similar hematocrit level, platelet count, and prothrombin time prior to surgery. The proportion of patients with hematoma involvement in the aortic root, aortic arch, or descending aorta was not significantly different between groups (Table 3). Of note, there were $5 \mathrm{IMH}$ patients who presented with acute indications for operative intervention who did not have surgery within 24 hours for various reasons, including prohibitively high operative risk. Patients with these findings were not included in the primary survival analysis comparing the 2 groups.

In logistic regression, there was no significant difference in the rates of complications between the 2 groups (Table 4). Prolonged intubation greater than 48 hours was common in both groups, affecting $66.7 \%$ of the early and $70.0 \%$ of the delayed intervention groups. The delayed intervention group did have higher rates of acute renal failure and atrial fibrillation, but these differences did not reach statistical significance. Rates of pneumonia and stroke were similar between the 2 groups. 
Table 3. Comparison between Patients Receiving Emergent or Delayed Surgery for Intramural Hematoma

\begin{tabular}{|c|c|c|c|}
\hline Demographics & Early* & Delayed* & $P$ \\
\hline Age, years (SD) & $60.0(17.8)$ & $66.2(12.9)$ & .515 \\
\hline Gender, male & $10(43.5 \%)$ & $4(36.4 \%)$ & .705 \\
\hline \multicolumn{4}{|l|}{ Ethnicity } \\
\hline White & $14(60.9 \%)$ & $6(54.5 \%)$ & .861 \\
\hline African American & $5(21.7 \%)$ & $4(36.4 \%)$ & .420 \\
\hline Body mass index & $29.7(6.8)$ & $30.3(4.5)$ & .886 \\
\hline \multicolumn{4}{|l|}{ Past medical history } \\
\hline Hypertension & $20(87.0 \%)$ & $9(81.8 \%)$ & .893 \\
\hline Diabetes & $5(21.7 \%)$ & $3(27.3 \%)$ & .954 \\
\hline Peripheral arterial disease & $1(4.3 \%)$ & $0(0.0 \%)$ & .327 \\
\hline Stroke & $6(26.1 \%)$ & $2(18.1 \%)$ & .851 \\
\hline Chronic lung disease & $1(4.3 \%)$ & $1(9.1 \%)$ & .728 \\
\hline End-stage renal disease & $1(4.3 \%)$ & $0(0.0 \%)$ & .330 \\
\hline Congestive heart failure & $1(4.3 \%)$ & $1(9.1 \%)$ & .661 \\
\hline Atrial fibrillation & $1(4.3 \%)$ & $0(0.0 \%)$ & .328 \\
\hline \multicolumn{4}{|l|}{ Preoperative lab results } \\
\hline Hematocrit, vol\% (SD) & $32.5(6.6)$ & $36.9(8.1)$ & .304 \\
\hline Platelet count, $\times 1000 / \mu \mathrm{L}$, no. (SD) & $182.0(63.6)$ & $147.6(52.1)$ & .334 \\
\hline INR (SD) & $1.14(0.12)$ & $1.12(0.28)$ & .876 \\
\hline \multicolumn{4}{|l|}{ Findings at presentation } \\
\hline Aortic regurgitation & $1(4.3 \%)$ & $1(9.1 \%)$ & .596 \\
\hline Coronary involvement & $1(4.3 \%)$ & $1(9.1 \%)$ & .596 \\
\hline Pericardial effusion & $5(21.7 \%)$ & $3(27.3 \%)$ & .732 \\
\hline Acute renal failure & $2(8.7 \%)$ & $1(9.1 \%)$ & .971 \\
\hline \multicolumn{4}{|l|}{ Hematoma location } \\
\hline Aortic root & $3(14.3 \%)$ & $3(30.0 \%)$ & .317 \\
\hline Ascending aorta & $8(38.0 \%)$ & $4(36.4 \%)$ & .298 \\
\hline Aortic arch & $14(66.6 \%)$ & $6(54.5 \%)$ & .260 \\
\hline Descending aorta & $12(57.1 \%)$ & $4(36.4 \%)$ & .279 \\
\hline
\end{tabular}

*Data is $\mathrm{n}(\%)$ unless otherwise indicated.

In Kaplan-Meier survival analysis, survival at 1 year was $97.7 \%$ for the early intervention group and $97.1 \%$ for the delayed intervention group (Figure). At 5 years, survival was $93.2 \%$ and $94.2 \%$ for the early and delayed groups, respectively. Log-rank test revealed no statistically significant difference between the 2 groups.

\section{CONCLUSIONS}

Our analysis demonstrated no increased morbidity associated with delayed operative intervention for type A IMH.
Table 4. Logistic Regression of Outcomes Comparing Emergent and Delayed Operations

\begin{tabular}{|c|c|c|c|c|}
\hline \multirow{3}{*}{ Outcome } & \multicolumn{2}{|c|}{ Estimate } & \multirow[b]{2}{*}{ Odds Ratio (95\% } & \multirow{3}{*}{$P$} \\
\hline & 5 & & & \\
\hline & & & & \\
\hline Pneumonia & $8.3 \%$ & $10.0 \%$ & $1.22(0.07-22.40)$ & .89 \\
\hline Stroke & $12.0 \%$ & $7.7 \%$ & $0.61(0.06-6.54)$ & .68 \\
\hline Acute renal failure & $23.1 \%$ & $30.0 \%$ & $1.43(0.22-9.26)$ & .71 \\
\hline Atrial fibrillation & $16.7 \%$ & $40.0 \%$ & $3.33(0.46-24.05)$ & .23 \\
\hline Prolonged intubation & $66.7 \%$ & $70.0 \%$ & $1.17(0.19-7.12)$ & .87 \\
\hline
\end{tabular}

Overall, both groups of patients did well, with 5 -year survival of greater than $90 \%$. Although the rates of renal failure and atrial fibrillation did appear to be higher in the delayed intervention group, these findings did not reach statistical significance, and there were no significant differences detected in any of the Society of Thoracic Surgeons major morbidities. Overall, these results suggest that in well-selected patients, delaying surgical repair of type A IMH does not increase the risk of morbidity or short- or long-term mortality.

However, as a retrospective, single-institutional series, this analysis faces several limitations. The results may not be generalizable, although the demographics and clinical characteristics of the patients studied appear fairly representative, and the management was similarly within the standard of care. The study population was small because acute type A hematomas are a relatively rare phenomenon. A large series would likely necessitate a multi-institutional study design. Patients were not randomized to a treatment strategy, and it is possible that surgeons chose patients with favorable characteristics for delayed surgical intervention. However, these findings highlight that, with proper patient selection, acceptable outcomes can be achieved with delayed management.

Although evidence is building that not every type A IMH requires emergent operative intervention, the optimal timing of surgery remains uncertain [Leshnower 2018]. IMHs do have the possibility of progressing into frank dissections, and groups have demonstrated that good outcomes can be achieved with early intervention [Matsushita 2016; Roselli 2016]. However, the likelihood and risk factors for this progression are unclear and warrant further investigation [Xie 2018]. In both our series and the International Registry of Aortic Dissection (IRAD), there are reports of patients with IMH who are successfully managed medically without surgery [Evangelista 2005]. As endovascular options for the proximal thoracic aorta continue to develop and improve, there has been interest in applying them to type A IMH, but currently, the evidence for this approach remains lacking [Sundt 2007].

Although other groups have demonstrated favorable results with delayed operative and sometimes medical management of IMH [Ferrera 2017], our study excluded patients who presented with radiographic evidence of both intramural hematoma and dissection to distinguish these 2 pathological processes. We believe it is important to view IMH and dissection 
separately in analyses of outcomes, given the potential difference in etiology between the 2 diseases. Although an IMH likely involves disruption of the vasa vasorum, because there is no injury to the intima, the theoretical risk of progression may be lower because the site of disease is not directly exposed to the shear stress of aortic blood flow [Sundt 2007].

Type A intramural hematoma may represent a different clinical and pathological entity than other acute aortic syndromes of the ascending aorta and aortic root, resulting in a diminished risk of immediate life-threatening complications. Delayed operative intervention strategy may be beneficial, especially in patients who are poor surgical candidates.

\section{REFERENCES}

Evangelista A, Mukherjee D, Mehta RH, et al. 2005. Acute intramural hematoma of the aorta: a mystery in evolution. Circulation 111(8):1063-70.

Ferrera C, Vilacosta I, Gómez-Polo JC, et al. 2017. Evolution and prognosis of intramural aortic hematoma. Insights from a midterm cohort study. Int J Cardiol 249:410-3.
Leshnower BG. 2018. Type A intramural hematoma: an unstable, unpredictable enigma. J Thorac Cardiovasc Surg 155(3):910-1.

Matsushita A, Fukui T, Tabata M, Sato Y, Takanashi S. 2016. Preoperative characteristics and surgical outcomes of acute intramural hematoma involving the ascending aorta: a propensity score-matched analysis. J Thorac Cardiovasc Surg 151(2):351-8.

Roselli EE, Svensson LG. 2016. Aggressive surgical repair for ascending intramural hematoma is still a great option. J Thorac Cardiovasc Surg 151(2):359-60.

Sandhu HK, Tanaka A, Charlton-Ouw KM, et al. 2016. Outcomes and management of type A intramural hematoma. Ann Cardiothorac Surg $5(4): 317-27$

Sundt TM. 2007. Intramural hematoma and penetrating atherosclerotic ulcer of the aorta. Ann Thorac Surg 83(2):S835-41; discussion S846-50.

Trimarchi S, Nienaber CA, Rampoldi V, et al. 2005. Contemporary results of surgery in acute type A aortic dissection: The International Registry of Acute Aortic Dissection experience. J Thorac Cardiovasc Surg 129(1):112-22.

Xie X, Bai J. 2018. Serial images demonstrating progression of type A intramural hematoma to type B aortic dissection. J Thorac Cardiovasc Surg 155(3):907-9. Especially see Video 2. 